\title{
The limitless Possibility of Combination: Filmic Lego Poetics of Storytelling and Structure in Global Film Scriptwriting and Duration
}

\author{
Chan Ka Lok Sobel \\ Academy of Film, School of Communication, \\ Hong Kong Baptist University, Hong Kong SAR, China
}

\begin{abstract}
Feature film is most limited in 90 mins in Chineselanguage films to 120 mins in Hollywood films in term of length and duration, and there are popularly summarizing in several film structures like 3 act, 4 act, 5 act structure, John Truby's story anatomy, Blake Synder's Beat Sheet, Christopher Vogler's Hero Journey, Paul's Sequence Approach, etc. the wellestablished film structure is well tested and practiced in film industry in term of box office, film comments and general audience' likeness and taste. It is so popular as it does suit the tastes and viewing habit of general audience. However, it will also limit the unlimited possibility of film structure and storytelling in another angle and how we perceive the film story concept. Therefore, this original and innovative paper would explore the interactive relationship and poetics between the length, duration and film storytelling and structure in a metaphysical and aesthetical form. If we can challenge or revisit the traditional film structure form, it may enlighten and explore the possibility of film art and our perception of film story. it may not just be about "problem and resolution" pattern. Everything can be possible like the bricks in Lego as film art is still very young in art historical aspect. Therefore, the paper challenges our traditional sense of frame to frame becoming shot, shot to shot becoming scene, scene to scene becoming sequence, sequence to sequence becoming act, and finally, act to act becoming film concept. It also challenges our long established understanding of how we view the film in 90 to 120 mins duration. In the end, the paper would propose a new paradigm or model of film structure.
\end{abstract}

Keywords: Classical Film Structure, Story Triangle, Slice of Life, Alternative Storytelling, Filmic Lego Poetics.

\section{Introduction}

The story structure of film is firstly determined by the duration and length of the film itself. In more than 100 years film history, begun with the short film, like Lumiere Brother 's short film or travelogue, it is no real film structure on it aesthetically, just running out the reel of films, then the film would be ended technically. The real sense of film structure may be cultivated and awaken from Sergei Eisenstein's montage, which emphasis on how the juxtaposition of frames and shots to produce another new meaning. It is like the mimic form of film structure in shot and shot scale and level. Not in the whole film duration spectrum. Another good highlight is D. W. Griffith's Intolerance, in this film, the whole film structure is divided by several stories, it is the milestone for modern multi-storytelling techniques.

To investigate closer, There are numerous differences between the feature and short film in terms of structure. Most obviously, the proportion of Acts 1, 2 and 3 , generally held to be 1: 2: 1 ( 30 mins to 60 mins to $30 \mathrm{mins}$ ) in feature film. It does not apply in short film. Act 1 is more likely to be 5 minutes in a short film. There will be no or very precise and brief middle act 2 , depending on the writer's choice of a solid resolution or an open ending. If the option for resolution is taken, the structure is Act1-Act3. If a more open-ended script is the choice, the structure looks like Act1-Act2. There also have other differences. In Act 1 in the feature film, there are key points-the critical moment (where you join the story), the catalytic event / inciting incident (where you kick-start the story), and the first major plot point (at the end of Act1). In the short film, all three aims or functions should be done in the same scene to save the time; at the very least, the catalytic event and the first major plot point are the same, the catalytic event can occur in 5 minutes on the script, at which point the first act is over. In the next act, we rush to resolution (act 3), or we explore options (act 2). Therefore, there are obvious and clear difference between short and feature film in term of structure, duration and how the story is told.

\section{Story Triangle}

Based on the important film scriptwriting scholar, Robert Mckee, He proposes the story triangle in his famous book. He categorizes the most stories in film into 3 classifications. The majority is Archplot, the others are miniplot and antiplot.

Classical Design (Archplot): Means a story built around an active protagonist who struggles against primarily external forces of antagonism to pursue his or her desire, through continuous time, within a consistent and causally connected fictional reality, to a closed ending of absolute, irreversible change. Most films focus on Archplot actually. Archplot is not about commercial or art, it is originated from human nature in daily life. Story Premise: What would happen if....?What is the story problem? Story problem is story premise, i.e. why we need to listen to story development, how to solve the story problem in the end? For example, Jaws, what would happen next if sharp is appearing on the beach and kill people? The function of structure is to provide progressively building pressures that force characters into more and more difficult dilemmas where they must take more and more difficult risk-taking choices and actions, 
gradually revealing their true natures, even down to the unconscious self. Pls refer to image 1 below:

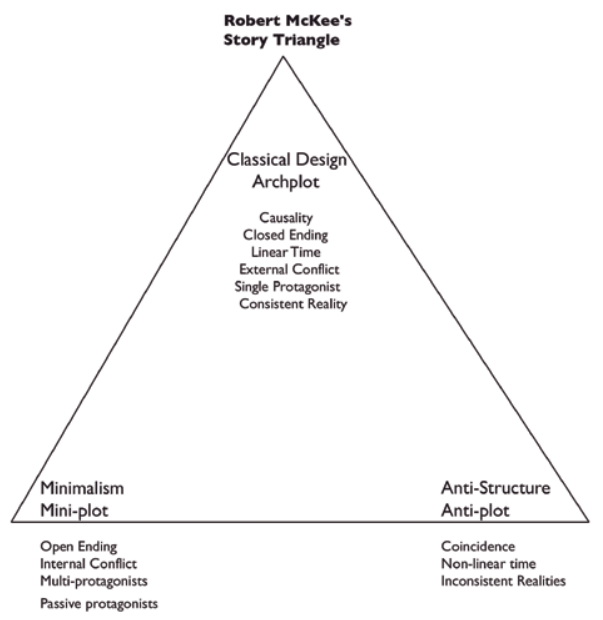

Image.1: from Robert Mckee's story.

For Miniplot, it is usually ended in openness, the multi-protagonists are so passive and struggle with his/her internal struggle psychologically. It refers to European films or some Asian art films like Taiwan New Cinema.

For Antiplot, the story is told by non-linear time and inconsistent realities. It also challenges the classical film forms, style and even the ideology of film making mechanism. It refers to Tout va Bien and Last Year at Marienbad, etc.

\section{Classical Film Structure for Archplot Story}

For a long time, different film scriptwriter and scholars tries very hard to study and practice how to tell the story best, in what format or pattern or structure a story can be told in the best effect. And actually, the meaning of "The Best" is rather arguable and problematic. As some stories, especially the mainstream Hollywood films, are more suitably told in more popular or entertaining way. While some stories, especially European film, or Taiwan New Cinema, should be told in rather alternative ways like slice of life or stream of sub-consciousness or even an experimental approach. In a nutshell, Archplot story (from Robert Mckee's term) is better told in traditional film structure: 3 acts structure, hero journey, beat sheet, sequence method and story anatomy,etc. Althougth this classification and catergory is very precise, it can be viewed in most film scriptwriting practice. This archplot structure is normally a linear narrative with strong causal logic and objective point of view. The narrator is like an invisible observer to know everything in narration. Sometimes, it may allow little pieces of flashback in black and white tone or brown tone.
The reasons behind why this classical film structure may be more suitable for popular story is based on the consonance of most human life experience. Most of us encounter facing and overcoming obstacle or downfalls in life. Most of people are afraid of leaving our comfort zone and also scared about taking risk into the so-called adventure journey or chaotic setting or disequilibrium world, etc. Finally, we all hope to win over it and get reward and rebirth at the end. This is so common as it is our shared life journey becoming or transforming into film story journey. However, this film structure is applied for so long time, and it is criticized for its clichés, generic conventions and formula without true creativity and originality. And 3, 4,5 acts film structure approaches is similar in the fundamental principle, probably with slight variations of the classical film structure.

Titanic must be one of the most famous example, Rose is the major protagonist in Titanic. She leaves her comfort zone in UK, and then takes the adventurous journey to get married in New York by the so-called unsinkable Titanic. During the 3 days and 3 nights journey, she meets Jack, and struggles with her triangle love and finally falls in deep love with Jack. And She leads a new life after arriving New York and Jack's death awaking her life pursuit and true value and identity. Titanic story is so touching that win over the global audience recognition for years. Some critics may comment the film structure of Titanic too simple and even over naïve, it is more like a romance fable in super-idealistic mindset, Hollywood dream and fantasy style. If we think about the realistic side of the Titanic story, how can Rose make a living in New York without the support of rich husband? Or how can Rose and Jack still be romantic in New York if Jack can't make a living as painter in New York? Pls remember Rose family is in big debt as her mother often warns Rose. However, a good story seems to un-tell or delete this realistic side of the story into formulaic 3 act film structure or heroic journey. One reason is about this is not so romantic and fairy tale. Another reason may be unfitting of the classical film structure approach. However, it is still popular and would be remade in sometimes in future.

\section{Daily Life Styled Film Structure for Miniplot Story}

On the other hand, miniplot is better told in slice of life ways. For example, Yi Yi, directed by Edward Yang, one of the most important Taiwan New Cinema Director, this film winning the best director in Cannes Film Festival. Slice of Life film structure and storytelling is seemingly arbitrary sequence of events in a character's life is presented, often lacking plot development, conflict and exposition. As well as often having an open ending (as life is still going). In Yi Yi, the duration of $\mathrm{Yi} \mathrm{Yi}$ is near $3 \mathrm{hrs}$, its duration is about 2 times of the so-called normal 90 mins or 120 mins feature film. It makes us reflect what the duration of film should last? If the duration of film greatly affects 
the types of story chosen and how the story is told, How long it should be? Yi Yi revolves around: major stages of life: marriage, childbirth, full moon wine, puberty, an affair (middle-age crisis, work pressure, tasteless marriage), funeral, etc. Film structure: from the beginning of the wedding to the end of the funeral. $\mathrm{Yi} Y i$ is a multiple storyline around family members. In the story, there are 7 sub-storylines: One: Jian Nanjun (played by Wu Nianzhen)'s wife (Minmin, Jin Yanling)'s younger brother (Adi) married Xiaoyan, and Qiandu (Ayun) came to the wedding to make disputes. 2: The mother-in-law was in a coma, and his wife (Minmin) entered the temple for retreat after this shock. Three: The entanglement between the daughter (Ting Ting), the fat man (Boyfriend), Ting Ting's same-sex friend (Lily). Four: Lili's English teacher has an affair with her mother (Mrs. Jiang). Five: Fat man kills the English teacher (maybe the English teacher has a sexual relationship with his girlfriend, Lily). Six: Yangyang (Jane's youngest son) likes female students. Seven: Jane meets his high school lover (Sherry) again at the wedding and Tokyo.

Movies are not simply a reproduction of life, nor the reproduction of daily life that we see with the physical eye. (If this is the case, Just living will be fine, why should we watch movies exactly like our lives?) Instead, Director Yang presents the "hidden meaning" of daily life that he has insight into with his heart and soul (the so-called: art is originated from life and is above the realm of life). Life is like ripples on a calm lake, woven into a net by accidental events. In the story, the mother-in-law, who is still in a coma, is a touch of magic before her passing, as if she has met Ting Ting, and strung up the secrets of the family members. It ironically reflects that family members don't know each other's concerns even living in the same apartment. The mother-in-law is the unspeakable listener, also as the role of audience for all family members in film storytelling.

Daily life film structure and storytelling is more suitable for family drama and setting in a rather slow pace of living style like Taiwan, some European cities Like French New Wave and Poland, etc. In Hong Kong cinema, I think Ann Hui's A simple Life and Summer Snow are good examples of daily life film.

\section{Non Linear Film Structure for Antiplot Story}

Alternative film structure can be referring to the non-linear narrative in most cases. It emphasizes on non-causal logic and occasional happenings. The time and place of events can be shattered and re-organized into new ordering. Sometimes, all flashback, flash-forward, memory, fantasy can be mixed freely. While anti-plot is more suitably told in stream of sub-consciousness or experimental ways as possible as it can be. One famous example must be Last Year at Marienbad, The story itself is anti-plot and like a mystery and metaphor. It is very hard to understand the anti-plot story itself only, and even harder to understand it with the stream of sub-consciousness. It mixed up the memory, present time, future, fantasy, dreaming and nightmare in a totally artistic freedom form in non-linear time and place. For some filmmakers, they would creatively tell the archplot story by the stream of sub-consciousness. like The Diving Dell and Butterfly, Inception, Memento, Tenet, 2046, Being John Malkovich, Eternal Sunshine of the Spotless Mind, etc.

Due to the memory and fantasy, there would be multi-version of story in film structure. There are 2 famous examples. First is The Double Life of Veronique, there are $2 \mathrm{act} / \mathrm{versions}$ of story in film. The first story is about a girl who can sing extremely beautifully like the angel's voice in Poland. Another story is about a female music teacher, who feel the uncertainty in life and lacking in love and passion in Paris. There is like the reflexive structure like mirror by the metaphor of blood, shoelace, music gift, a tree symbolic to her reliable father, teabag, EKG graph, marionette, etc. the film focuses on the innermost minds, spiritual feeling, and senses of characters herself, etc. and the mysterious human relationship are linked together and affected their life deeply and interactively. There is no clear causal relationship, sensational effect, SFX, climax/catastrophe, problem and resolution approach in the ending.

Another significant example is Run Lola Run by Tom Tykwer, 1998. It is Germany thriller film. And starring Franka Potente as Lola and Moritz Bleibtreu as Manni. The story is also multiple narrative and version of the 3 times running by Lola. Precisely, it is the same dramatic situation, with 3 different running version, it emphasizes on how the coincidence, accidents, common people/bystanders can affect or connect with your life and fate or you affect them as well, it is not your closest relative, parents or lover or friends who affect you importantly, it is not the very concrete causal connection in traditional cinematic narrative structure. The film touches on themes such as free will vs. determinism, the role of chance in people's destinies, and unclear cause-effect relationships. Through the brief flash-forward sequences of still images, Lola's fleeting/brief interactions with bystanders are revealed to have surprising and drastic effects on their future lives, serving as concise illustrations of butterfly effect.

Structurally, the film structure can be destructed as below: Prologue-First run, second run, third run, with flash-forward sequences in each run. The thematic exploration of free will vs. determinism is made clear from the start. In the film's brief prologue, an unseen narrator asks a series of rhetorical questions that prime the audience to view the film through a metaphysical lens touching on traditional philosophical questions involving determinism vs. philosophic libertarianism. Each run contains various flash-forward sequences, showing how the lives of the people that Lola bumps into developing after the encounter. In each run, those people are affected in different ways. 


\section{First run:}

Fatally wounded, Lola recalls a conversation with Manni about their love. Struggling to tell Manni she wants to leave him, the movie returns to a dying Lola. She refuses to die, and the film then reverts to their phone call at the beginning of the film.

\section{Second run:}

Manni holsters his gun and walks to Lola, only to be hit by the ambulance, fatally wounding him. Manni recalls asking Lola how she would cope with his death. The film briefly returns to the present day and shows Manni refusing to die before restarting once more at the beginning of Lola's run.

\section{Third run:}

Lola reaches the supermarket, but cannot find Manni. A car then pulls up containing Manni and Ronnie, who shake hands. Manni, no longer in need of the 100,000 marks, asks Lola what is in the bag she is carrying, only for the film to end in a freeze-frame on Lola's reaction in an elliptical instant before a possible flash-forward.

Multiple version of story is symbolized by the recurring images of spirals, such as the 'Spirale' Cafe behind Manni's phone box and the spiral staircase down which Lola runs. Moreover, it explains why we have multiple version of life, because nowadays, we have known the parallel universe in scientific theory and internet theory. This theory also affects creativity. For example, Matrix, Interstellar, Blind Chance, Sliding Doors, Rashomon, Source Code, etc.

\section{Filmic Lego Poetics for New Form of Storytelling}

Traditionally, story in film is completed by the whole film duration. And each scene is linked/edited with each scene to construct a whole film story. Each scene is like a mini-story indeed. What if a single scene is like the single brick in Lego, that means it is so neutral in the sense, it can mix and match together to create the limitless possibility of combination of film structure, far beyond the framework of linear or non-linear narration and structure in the past. In doing so, the concept of film story would be also changed or goes into new horizon with new imagination and creativity. And eventually, the film duration would also be altered based on the shape of filmic Lego poetics, the breadth and depth of story type and genre would also be greatly changed and broaden.

Besides changing the duration and shape of film structure, it will also consider and challenge the point of view and the level of insight. Normally, most stories will be told by first person point of view, for example, Rose in Titanic. It means that Rose tells her titanic story by her own point of view. So her monologue is heard. Other examples are Forrest Gump and American Beauty, etc. The second person point of view is seldom seen on film, the significant example is Last Action Hero, the narrator is the kid movie fan himself, actually, his role is replacing the point of view of audience. The third person narrator is him or her. For example, Her is in Amelie. Sometimes, the narrator can be shifted. The Sixth Sense, the male protagonist does not know he is already dead. Or the narrator is also a liar. For example, In the heat of the Sun, and One Flew over the Cuckoo's nest and Jacob's Ladder, etc. Besides the narrator, who is listening is also very critical and important, audience is in the judge position in Rashomon or The mother in law is in coma situation in $\mathrm{Yi} Y \mathrm{Y}$, etc.

Another issue is the level of insight, that is how much the narrator know? Omni present means the narrator is like the god who knows all the character's thought. Sometimes, the omni-present narrator would tell the story in voice-over form. Beside it, limited omni-present narrator means that the narrator only know what the main character is thinking.

What if a scene is like a brick in Lego, it may also alter the point of view and level of insight in films. For scene brick is so neutral, it can transform into several character's point of view.

\section{What a Good storytelling is?}

In contemporary times, many famous film directors understand: The critical point for a good movie is not just to tell a story? The key point is how to tell the story best? In particular, Christopher Nolan, the British film director who has the highest salary for a contemporary global director, understands this well and does not stick to traditional narrative techniques. He has already played a "narrative game" in his name card film "Memento", asking the audience to go into a maze by reorganizing the "losing memory of the real murderer" . as the protagonist is suffering from transient amnesia. This idea is already very much in itself. The most innovative thing is to break the logic of the usual audience watching movies (black and white scene is the forward sequence, while color scene is the flashback). Other well-known examples: "Tenet" also playing on the reverse temporal narration, "Rashomon", "Run Lola Run", "The Double Life of Veronique", "2046", "In the Mood for Love", "Being John Malkovich", "The Spotless Mind of Eternal Sunshine", "Diving Bell and Butterflies" and so on.

In the global film market, movies applying Hollywood storytelling method can sell well and also get the favorite of the general public. what unique storytelling method is used to make Chinese language film stories most appealing? This is a major topic that will take a lifetime and several generations to study. As a filmmaker like scriptwriter and director, you need to always challenge your creativity. After all, how many possibilities are there for the same story? In fact, how to tell a story, the real secret is how the creator understands and reconstruct the "life experiences". 


\section{Bibliography}

Mckee, Robert.1997. Story: Style, Structure, Substance, and the Principles of Screenwriting. U.S.A: Regan Book.

\section{Filmography}

Intolerance (1916)., Directed by D.W. Griffith. Tout va Bien (1972)., Directed by Jean Luc Godard. Last Year at Marienbad (1961)., Directed by Alain Resnais.

Titanic (1997)., Directed by James Camerson.

Yi Yi (2000)., Directed by Edward Yang

The Diving Dell and Butterfly (2007)., Directed by Julian

Schnabel

Inception (2010)., Directed by Christopher Nolan

Memento (2000)., Directed by Christopher Nolan

Tenet (2020)., Directed by Christopher Nolan

2046 (2004)., Directed by Wong Kar Wai

Being John Malkovich (1999)., Directed by Spike Jonze

Eternal Sunshine of the Spotless Mind (2004)., Directed

by Michel Gondry

The Double Life of Veronique (1991)., Directed by

Krzysztof Kieslowski

Run Lola Run (1998)., Directed by Tom Tykwer

Matrix (1999)., Directed by The Wachowski Brothers

Interstellar (2014)., Directed by Christopher Nolan

Blind chance (1987)., Directed by Krzysztof Kieslowski

Sliding Doors (1998)., Directed by Peter Howitt

Rashomon(1950)., Directed by Akira Kurosawa

Source Code (2011)., Directed by Duncan Jones

Forrest Gump (1994)., Directed by Robert Zemeckis

American Beauty (1999)., Directed by Sam Mendes

Last Action Hero (1993)., Directed by John McTiernan

Amelie (2001)., Directed by Jean-Pierre Jeunet

The Sixth Sense (1999)., Directed by M. Night

Shyamalan

In the heat of the Sun (1994)., Directed by Wen Jiang

One Flew over the Cuckoo's nest (1975)., Directed by

Milos Foreman

Jacob's Ladder (1990)., Directed by Adrian Lyne

\section{Author and Institution}

Dr. Chan Ka Lok Sobel

Senior Lecturer and Associate Programme

Director and Scriptwriting Thesis Project Supervisor of Master of Fine Art in Film, Television and Digital Media Programme

Academy of Film, Hong Kong Baptist University, HKSAR, China

Email: sobelc@hkbu.edu.hk

Mailing address: acc206, Hong Kong Baptist University, Kowloon Tong, Hong Kong

\section{Brief Biography}

Sobel Chan ka lok is a senior lecturer of Academy of film, Hong Kong Baptist University, former assistant professor and programme coordinator of English Communication in Macao University. Where his research and teaching focuses on screenwriting, Chinese-language film, Hong Kong and Taiwan Cinema, Film Directing, Film Production for Master of Fine Arts in Film, Television and Digital Media. He is the author of The Politics of Representation: Cultural Identity and Political Events in Hong Kong Cinema, Studies on Hong Kong Film, Television and New Media, Scriptwriting Handbook, Hong Kong Film: Nostalgia and Ideology, and How to write a film review, Hong Kong Television Creative Guidebook, Gospel Message and Cinema Therapy: Cinema and Christianity, etc. 